\title{
Cytopathological changes on conjunctival impression cytology in computer users
}

\author{
Pooja. H. V. 1,*, H. T. Venkate Gowda ${ }^{2}$ \\ ${ }^{1}$ Senior Resident, ${ }^{2}$ Professor and HOD, Dept. of Ophthalmology, Adichunchanagiri Institute of Medical Sciences, Mandya, Karnataka, \\ India \\ *Corresponding Author: Pooja. H. V \\ Email: poojahv1410@gmail.com
}

\begin{abstract}
Purpose: To evaluate the cytological changes in conjunctiva in computer users and a control group.

Materials and Methods: 28 eyes of an age and sex matched control group were studied by conjunctival impression cytology (CIC). Written informed consent was taken from all the participants. Best corrected visual acuity (BCVA), slit lamp examination (SLE), fundoscopy, Schirmer test, TBUT, CIC was done in all. H\& E staining was carried out on the cellulose acetate strips and morphological changes in epithelial cells, nucleocytoplasmic ratio and goblet cell density were looked into and graded according to Nelson grading. ${ }^{3}$ The data was analysed using SPSS version 16.0. Results were expressed as frequency and percentage. Means of groups were compared using ttests.

Results: Mean age (in years) in computer users was $24.42 \pm 2.18$; controls $23.25 \pm 2.36(\mathrm{p}=0.632$ ). Out of 14 participants in each group (28 eyes in each) 15 were males and 13 were females. There was no significant difference with respect to sex in both the groups. Computer users showed CIC results between grade 2 to 3 . Whereas control group showed grade 0 and 1 .
\end{abstract}

Conclusion: Dry eye was more common in computer users and we found more CIC changes in them.

Keywords: Impression cytology, Computer users, Dry eye.

\section{Introduction}

Dry eye has become common among computer users. Conjunctival impression cytology (CIC), a non-invasive simple technique has been employed to examine the conjunctival changes in dry eye. ${ }^{1,2}$

\section{Materials and Methods}

The study was conducted from Feb - June2018.Ethical clearance has been taken from the institution ethics committee. The study was mainly targeted across our university/ medical students, non teaching staff and involved 28 eyes of computer users who had used computers for more than 1 year (4-10hrs/ day) and 28 eyes of an age and sex matched control group were studied by CIC after obtaining written informed consent. Cases that were excluded were contact lens users, postoperative (Pterygium, Cataract, Keratoplasty, Glaucoma, LASIK), chronic lid abnormalities, blistering disorders, chemical injuries, patients on certain drugs like antiglaucoma medications, TCAs, OCPs, diuretics and certain systemic disorders which were clinically suggestive of Sjogren's syndrome, Rheumatoid arthritis, Parkinson, Lupus,
Hypothyroidism, Diabetes. Best corrected visual acuity (BCVA), slit lamp examination (SLE), fundoscopy, Schirmer test, tear film break-up time (TBUT), conjunctival impression cytology (CIC) was done in all.

Technique of CIC: CIC was performed after instilling the eye with one drop of $0.5 \%$ proparacaine. The excess lacrimal lake at the medial canthus was dried with a cotton. A $2 * 2 \mathrm{~mm}$ cellulose acetate paper was grasped with a blunt tipped forceps and placed on the inferior bulbar conjunctiva. The paper strip was gently pressed and the filter paper was removed in a peeling fashion after 4 seconds and the specimen was sent to the lab for fixation and staining. The filter paper was then removed from the slide and the slide labelled. The slide was kept at room temperature stained with hematoxylin and eosin. H\& E staining of the slides thus obtained was done and morphological changes in epithelial cells, nucleocytoplasmic ratio (N:C) and goblet cell density was assessed and graded according to Nelson grading. ${ }^{3}$ (Table 1). The data was analysed using SPSS version 16.0. Results were expressed as frequency and percentage. Means of groups were compared using t-tests.

Table 1: Nelson's grading system for impression cytology

\begin{tabular}{|l|c|c|}
\hline Grade & Goblet cell characteristics & Epithelial cells characteristics \\
\hline 0 & Normal density & Normal cells \\
\hline 1 & Decreased density & Reduced nucleocytoplasmic ratio (1:3) \\
\hline 2 & Absence of cells & Larger cells with a nucleocytoplasmic ratio 1:4 to 1:5 \\
\hline 3 & $\begin{array}{c}\text { Absence of cells plus squamous } \\
\text { metaplasia }\end{array}$ & $\begin{array}{c}\text { Cells with a large eosinophilic cytoplasm with folded } \\
\text { edges and pyknotic nuclei (nucleocytoplasmic ratio 1:6) }\end{array}$ \\
\hline
\end{tabular}

\section{Results}

Mean age (in years) in computer users was $24.42 \pm$ 2.18; controls $23.25 \pm 2.36(\mathrm{p}=0.632)$. Out of 14 participants in each group (28 eyes in each) 15 were males and 13 were females. Mean Schirmer test values in computer users was $24.34 \pm 8.64 \mathrm{~mm}$ and $31.66 \pm 6.74$ in 
controls. Mean TBUT in computer users was $11.06 \pm 2.42$ and in controls it was $14.86 \pm 3.62$ seconds. $53 \%$ of computer users had grade 0,1 on CIC; $41 \%$ had grade 2 and $6 \%$ grade 3 . On the contrary, $92.5 \%$ of the controls had grade 0,1 on CIC. (Table 2) Computer users showed CIC results between grade 2 to 3 .Whereas control group showed grade 0 and 1 .

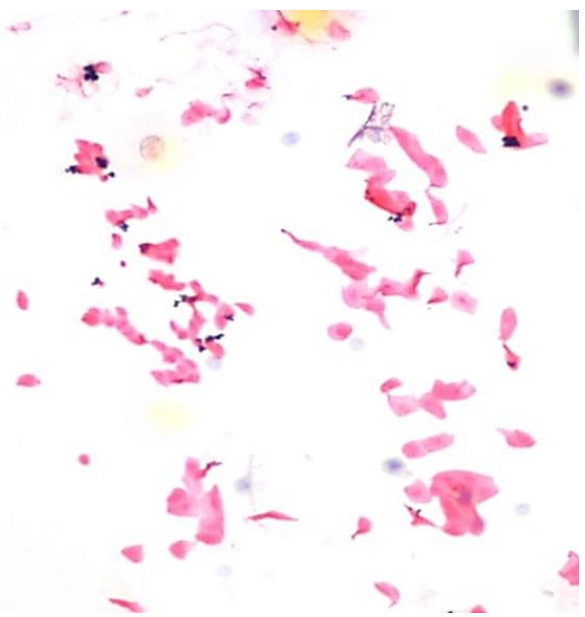

Fig. 1: Shows squamous cells with goblet cells indicating Nelson grade 0

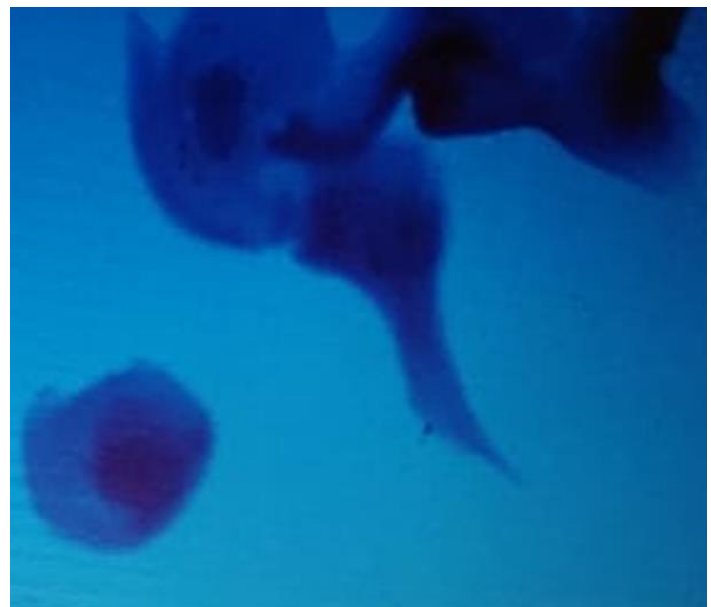

Fig. 2: Shows goblet cells

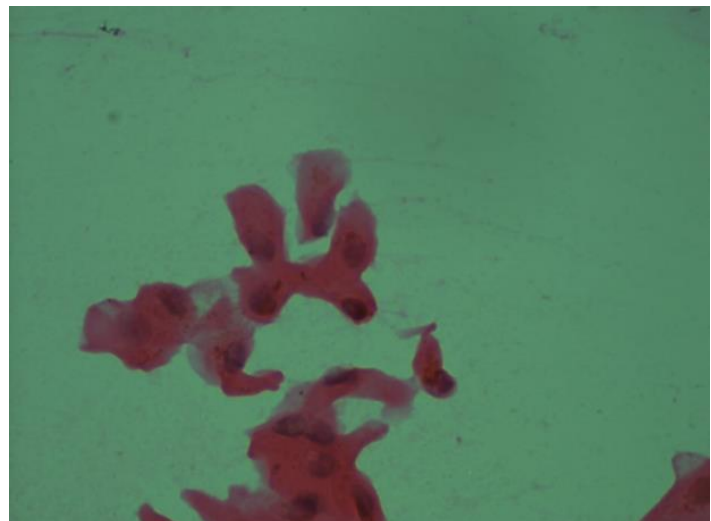

Fig. 3: Shows squamous cells with $\mathrm{N}$ :C of 1:3, sparse goblet cells indicating Nelson grade 1

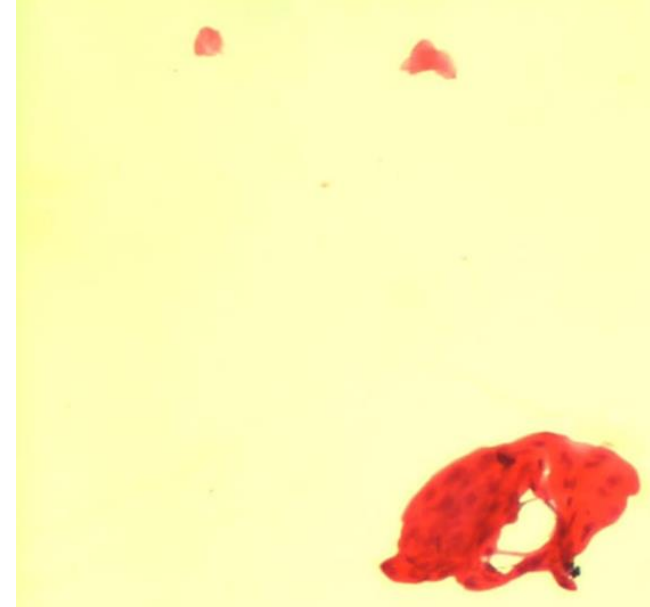

Fig. 4: Shows squamous cells with $\mathrm{N}: \mathrm{C}$ of 1:4 indicating Nelson grade 2

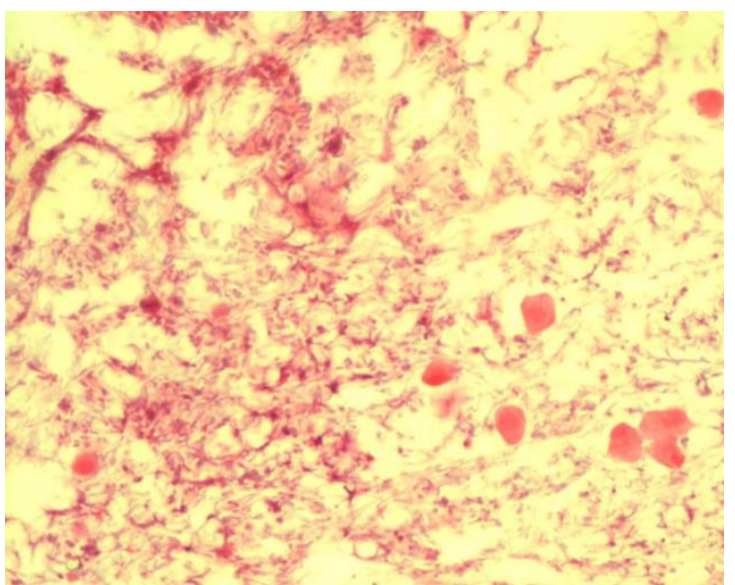

Fig. 5: Shows squamous epithelial cells with pyknotic nucleus, N:C of 1:6 indicating Nelson grade 3

Table 2: Conjunctival impression cytology grading in computer users and controls

\begin{tabular}{|l|c|c|c|}
\hline & Grade 0, 1 & Grade 2 & Grade 3 \\
\hline $\begin{array}{l}\text { Cases } \\
28 \text { eyes }\end{array}$ & $15(53 \%)$ & $11(41 \%)$ & $2(6 \%)$ \\
\hline $\begin{array}{l}\text { Controls } \\
28 \text { eyes }\end{array}$ & $26(92.5 \%)$ & $2(7.5 \%)$ & - \\
\hline
\end{tabular}

\section{Discussion}

The role of computers and internet has tremendously increased in our daily life. Prolonged usage is known to cause dryness of eyes. ${ }^{4,5}$ CIC being noninvasive, easily learned, an outpatient procedure which causes no /less discomfort. Diagnosis of dry eye is a tedious task and despite limitations of routine tear function tests employed, conjunctival impression cytology has not yet been recommended as the first line investigation in dry eye, as it is relatively time consuming. Morales- Ferandez et al suggested impression cytology as a valuable test in the 
diagnosis of dry eye. ${ }^{6}$ In the present study we evaluated the outcomes following long working hours on computers on cytological changes on CIC in computer users as compared to controls. In our study, computer users showed CIC results between grades 2 to 3. Whereas control group showed grade 0 and 1. Bhargava et al showed evidence of dry eye in computer users on CIC. (2 Kumar et al in their study showed nearly $>90 \%$ of computer users had grade $2-3$ on CIC. ${ }^{3}$ Kumar $\mathrm{P}$ et al, Shreshtha et al conducted a case control study and demonstrated reduced goblet cell density in dry eye individuals. ${ }^{7,8}$ Mukhopadhyaya et al found abnormal CIC in computer users who used for more than 8 hours per day. ${ }^{9}$ The present study highlights the importance of screening for dry eye through impression cytology in young individuals who work more on computers these days.

\section{Conclusion}

Dry eye was more common in computer users and we found more CIC changes in them. CIC helps in diagnosis in sub clinical and relatively asymptomatic stage and hence if managed early potential corneal complications can be prevented. The limitation of our study was small sample size.

\section{Acknowledgement}

Department of Pathology, AIMS, B.G. Nagar.

\section{Conflict of Interest: Nil.}

\section{References}

1. Bhargava. R, Kumar. P, Kaur A, Kumar M, Mishra A. Dry eye symptomatology versus tear film tests in computer users. J Lab Physicians. 2014;6(2):102-108.
2. Kumar S, Bansal R, Khare A. Conjunctival impression cytology in computer users. Nepal J Ophthalmol. 2013; 5(9): 33-7

3. Nelson JD, Havener VR, Cameron JD. Cellulose acetate impressions of the ocular surface. Dry eye states. Arch Ophthalmol. 1983;101:1869-1872.

4. Bhargava R. Kumar P. Conjunctival Impression cytology in computer users. Int J Ophthalmic Pathol. 2014;3(4).

5. Rosenfield M. Computer vision syndrome: a review of ocular causes and potential treatments. Ophthalmic Physiol Opt. 2011.31;502-515.

6. Morales- Fernandez L, Perez Alvarez J, Garcia- Catalan R, Benitez- del-Castillo JM, Garcia Sanchez J. Clinical and histological correlation in patients with dry eye. Arch Soc Esp Oftalmol. 2010;85(7):239-245.

7. Kumar P, Bhargava R, Kumar M, Ranjan S, Kumar M, Verma $\mathrm{P}$. The correlation of routine tear function tests and conjunctival impression cytology in dry eye syndrome. Korean J Ophthalmol. 2014;28:122-129.

8. Shreshtha E, Shreshtha JK, Shayami G, Chaudhary M. The conjunctival impression cytology between the diagnosed cases of dry eye and normal individuals. Nepal J Ophthalmol. 2011;3(5):39-44.

9. Mukhopadhyaya S, Dutta J, Mitra J, Prakash R, Datta H. An impression cytology based study of ocular surface in an urban population. Int Ophthalmol. 2013;33:153-157.

How to cite this article: Pooja. H. V, Gowda H. T. V. Cytopathological changes on conjunctival impression cytology in computer users. Int $\mathbf{J}$ Ocul Oncol Oculoplasty. 2018;4(4):163-165. 